Volume 7, No.2, April - June 2018

International Journal of Computing, Communications and Networking

Available Online at http://www.warse.org/ijecn/static/pdf/file/ijecn35722018.pdf

https://doi.org/10.30534/ijccn/2018/35722018

\title{
COSTEFFECTIVE VOICE CONTROLLED SMART SYSTEM USING PI3 b AND ECHO-DOT
}

\author{
Prof. Chandan Raj B R ${ }^{1}$, Rohith Kumar $N^{2}$, Sangamesh ${ }^{3}$, Shravan Kumar K S ${ }^{4}$, Suraj B $M^{5}$ \\ ${ }^{1}$ Associate professor EWIT, India, chandanraj@ewit.edu \\ ${ }^{2}$ Student, EWIT, India, rohith000kumar@gmail.com \\ ${ }^{3}$ Student, EWIT, India, sangameshkamalapure@gmail.com \\ ${ }^{4}$ Student, EWIT, India, shravankumar.sk50@gmail.com \\ ${ }^{5}$ Student, EWIT, India, suraj.hadpad96@ gmail.com
}

\begin{abstract}
Voice controlled smart system that allow users to control electric appliances of various kinds like fan, lights etc. The benefits are energy savings, convenience, security, home entertainment. In this project, we present an overview of voice controlled smart system using raspberry pi3b which acts as a smart device with the help of echo dot which allows us to control multiple devices such as lights and fan connected to Raspberry pi 3 attached relay with voice commands from Alexa [artificial intelligence available in echo-dot]. Using Raspbian as an operating system on raspberry pi3 and using python as programming language in the back end to enable and disable the GPIO pins of the raspberry pi3 board which is connected to relay that acts as switches to the connected devices.
\end{abstract}

Keywords: IOT, Raspberry pi, Echo Dot, GPIO

\section{INTRODUCTION}

Our project is built upon the on the concept of Internet of Things. We have determined to implement seamless integration of all the appliances in the home via a central console. The project greatly changes the way in which we communicate with our home appliances. It also reduces the need for any personal contact with any of them as it delivers a wholesome experience of wireless, voice controlled system. We plan to implement this project with the aid of Raspberry pi3 boards with the capability to perform IoT (Internet of Things) operations. Installing the boards in every appliance of the house will allow us to establish real-time communication with them via Wi-Fi.

Raspberry pi3 was primarily designed for practical and economic solution for innovators seeking to create Wi-Fi enabled projects with minimal pre-requisite knowledge in the field. It is built upon the 64-bit quad-core ARM Cortex-A53 processor (System on Chip), that specializes in IoT (Internet of Things) projects and devices.

\section{Key benefits of 64-bit quad-core ARM Cortex-A53 processor}

[1] High efficiency processor for a wide range of applications in mobile, DTV, automotive, networking, storage, aerospace, and more.

[2] High value Armv8-A architecture for standalone entry level designs.
[3] Versatile, can be paired with any Armv8.0 core in a big. LITTLE configuration, including Cortex-A57, Cortex-A72, other Cortex-A53, and Cortex-A35 processors.

[4] Mature product with high volume shipment.

This processor can also be implemented in an Arm big. LITTLE configuration.

\section{RELATED WORK}

This is a voice based home automation system in which user can interact with the system remotely through echo dot over the Internet. Home appliances like lights, fans, door locks, air conditioners, etc. are remotely controlled.

Amazon Echo, is a device that serves as a personal assistant. It takes as input any query and provides a response to the user. It can be integrated with IFTTT recipes and developers can develop "skills" for Amazon Echo and deploy it. A skill is essentially a service (like apps for mobile phones) that can be published by developers and can be used by all. We believe that it is not cost- effective to be adopted universally. Further, we believe that if these systems are voice controlled, it will make these systems more user friendly. We decided to go ahead with using Amazon Echo because of the option to develop skills. We also use Raspberry $\mathrm{Pi}$ [11] as the hardware component and it costs about USD 50. Overall, our system will work out to be more cost effective compared to existing systems out there today.

\section{PROPOSED SYSTEM}

This system aims at developing a Voice controlled smart system which mainly focuses on monitoring and controlling non smart devices over wired and wireless networks. The system consists of two main parts: A hardware interface module and a software communication module. The Hardware interface module consists of: Raspberry pi 3, WiFi module and relays.

The central device is the Raspberry pi 3 that connects to the Wi-Fi module and receives orders from Echo-dot to monitor and control the non-smart devices. 


\section{A. COMPONENTS}

\section{Raspberry Pi}

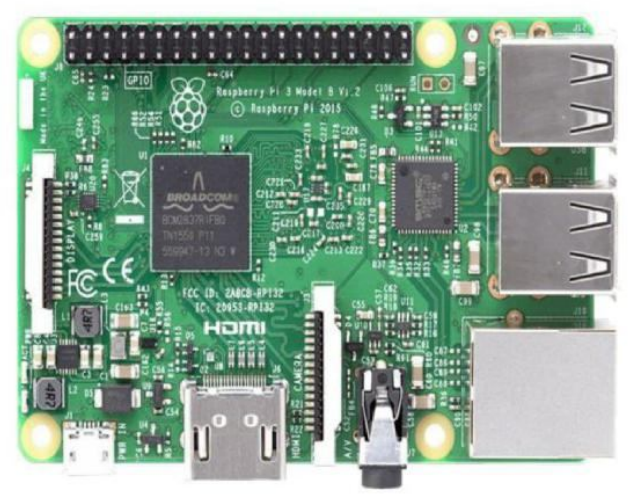

Fig 3.1 Raspberry Pi

The Raspberry $\mathbf{P i}$ is a series of small single-board computers developed in the United Kingdom by the Raspberry Pi Foundation to promote the teaching of basic computer science in schools and in developing countries. The original model became far more popular than

anticipated, selling outside its target market for uses such as robotics. It does not include peripherals (such as keyboards, mice and cases). However, some accessories have been included in several official and unofficial bundles.

\section{Relay}

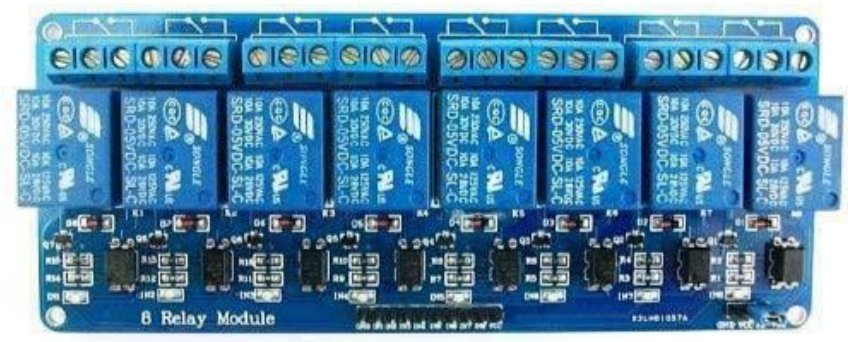

Fig 3.2 Relay module

A relay module is used to turn on or turn off home appliances using voltage and/or current much more than Arduino could handle. This is also used for providing isolation between the low voltage circuit on Arduino side and the high voltage circuit side controlling home appliances. Relay module is activated by using external $5 \mathrm{~V}$ power supply, which in turn, controls electrical appliances like fans, lights, ovens etc.

\section{Echo Dot}

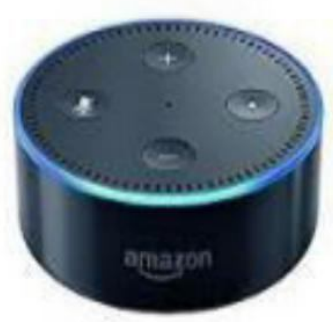

Fig 3.3 Echo Dot

The Amazon Echo is a hands-free speaker controllable by voice commands. It connects to Amazon's Alexa Voice Service, which can play music, read the news, provide weather reports, set timers, and even order a pizza when asked to. The Echo has seven microphones to detect your voice from across the room and can clearly detect commands even when music is playing or other sounds interfere.

\section{LITERATURE SURVEY}

According to survey we found that some systems are working with the help of internet, cloud server, web browser.

\subsection{Sensor Based Home Automation and Security System.}

This is a web based home automation system in which user can interact with the system through a web-based user interface over the Internet. Home appliances like lights, door locks, air conditioners and gates are remotely controlled through a user-friendly web page.

\section{2. i-Learning IoT: An Intelligent Self Learning System for Home Automation Using IoT}

In this system, Home automation is working on cloud principle. With the help of different sensors, monitoring is done. A computer is kept permanently active at home. That computer is there to control the operations with home appliances. 
Home PC is kept to continuous monitor sensor output. If there is any problem found with the output given by sensors, Home pc is going to report that problem to Cloud Server. Home PC is responsible for conveying messages towards cloud server. Cloud server will store the information into the database and will take actions according to output.

\subsection{Smart Home System Using Android Application.}

In SMS based Smart home concept has the main control which implements GSM to provide remote access from PC/laptop. The design consists existing electrical switches and with low voltage activating method provides more safety control in the switches. The switches status is synchronized in all the control system whereby the real time existing switches status is indicated by every user interface. The purpose of system is to control electrical appliances.

\section{IMPLEMENTATION}

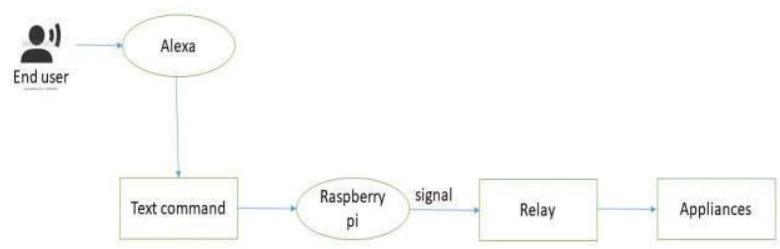

Fig 5 Data Flow Diagram

To power up the raspberry pi, we connect it to a $5 \mathrm{~V}, 2 \mathrm{~A}$ micro USB charger. The raspberry pi board, echo dot are connected to the same Wi-Fi network, the python code is fed into the memory of raspberry pi, there are several GPIO pins on the raspberry pi board which are used to send the output signal from the raspberry pi board to the relay module For ex: Pin 2 on the raspberry pi board is used for power supply to the relay module and pin 6 can be used as ground, Other GPIO Pins can be used to send input and output signals to the relay module.
The devices connected to the relay are connected in such a way that so that they are connected between the middle (common) and end (normally open) ports of the relay and the other ends is connected to the device and the mains (power source).

\section{RESULT}

The Echo dot device receives commands from the user and checks if the command is valid, if the command is valid then it sends the command to the raspberry pi board over the internet

raspberry pi which receive the command, processes and depending on the command it sends the control signal to the relay board which is attached to raspberry pi. Depending on the control signals received by the raspberry pi, the relay toggles between on and off states, depending on the state of the relay, the current either flows through it or doesn't flow which helps in either turning on or off a device connected to the relay.

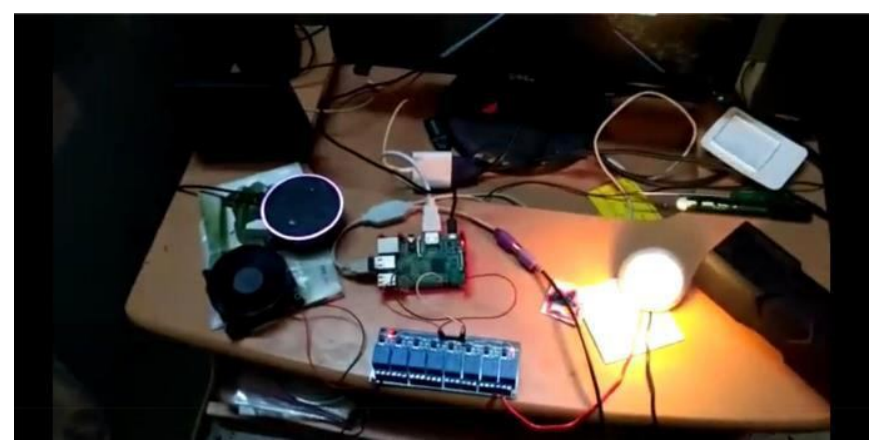

Fig 4 Implementation of system

\section{CONCLUSION}

Home automation market is very auspicious sector which is developing rapidly. It requires extensive range of developments that can be made in the idea of smart homes. The smart home space has a lot of interesting challenges to be solved. One very important problem that we tried to address in this paper is that of smart home security. We made use of one of the hottest smart devices available today in the market, Amazon Echo and coupled it with the Raspberry Pi. We believe that this a step towards a costeffective smart home security solution.

\section{REFERENCES}

[1] Subhajit Dey, "Web based real-time home automation and security system", International Journal of Electrical and 
Chandan Raj B R et al., International Journal of Computing, Communications and Networking, 7(2) April - June 2018, 193-196

Electronic Engineering \& Telecommunications, Volume 4, No 3, July 2015.

[2] Nathan David, Abafor Chima, Aronu Ugochukwu, "Design of a Home Automation System Using Arduino", International Journal of Scientific \& Engineering Research, Volume 6, Issue 6, June-2015

[3] Mukesh Kumar, Shimi S.L,” Voice Recognition Based

Home Automation System for Paralyzed People",International Journal of Advanced Research in Electronics and Communication Engineering (IJARECE) Volume 4, Issue 10, October 2015.

[4] Y Uzunay and K Bicakci, "SHA: A secure voice activated smart home for quadriplegia patients," 2007 IEEE International Conference on Bioinformatics and Biomedicine Workshops, Fremont, CA, 2007, pp. 151-158.

https://doi.org/10.1109/BIBMW.2007.4425413

[5] DF Syu, SW Syu, SJ Ruan, YC Huang and CK Yang, "FPGA implementation of automatic speech recognition system in a car environment," 2015 IEEE 4th Global Conference on Consumer Electronics (GCCE), Osaka, 2015, pp. 485-486.

https://doi.org/10.1109/GCCE.2015.7398519

[6] Manikandan J., "Design and evaluation of wireless home automation systems," 2016 IEEE 1st International Conference on Power Electronics, Intelligent Control and Energy Systems (ICPEICES), New Delhi, India, July 2016. https://doi.org/10.1109/ICPEICES.2016.7853323

[7] Anandhavalli D, Noorul S. Mubina, Bharathi P, "Smart Home Automation Control using Bluetooth and GSM.", International Journal of Informative and Futuristic Research, Volume 2, Issue No. 8,April-2015.

[8] Ahmad, B. I., Yakubu, F., Bagiwa, M. A and Abdullahi, U. I., Remote Home Management: An alternative for working at home while away. World of Computer Science and Information Technology Journal (WCSIT), 1, 4, 144147, 2011.

[9] Syed Mujeeb Patel, Syed Jilani Pasha, "Home

Automation System (HAS) using Android for Mobile Phone.'International Journal of Scientific Engineering and Technology Research, Volume.04, IssueNo.25, July-2015, Pages: 4844-4849.

[10] Erik Brynjolfsson and Andrew McAfee, "The Second

Machine Age: Work, Progress and Prosperity in a Time of Brilliant Technologies", 2014.

[11] Rozita Teymourzadeh, Salah Addin Ahmed, Kok Wai Chan, and Mok Vee Hoong, "Smart GSM Based

Home Automation System", 2013 IEEE Conference

on Systems, Process \& Control (ICSPC2013).

https://doi.org/10.1109/SPC.2013.6735152

[12] Sonali Sen, Shamik Chakrabarty, Raghav Toshniwal, Ankita Bhaumik, "Design of an Intelligent Voice Controlled Home Automation System", International Journal of Computer Applications (0975 - 8887) Volume 121 - No.15, July 2015.
[13] Mahesh N. Jivani, "GSM Based Home Automation System Using App-Inventor for Android Mobile Phone”, International Journal of Advanced Research in Electrical, Electronics and Instrumentation Engineering, Vol. 3, Issue 9, September 2014.

[13] Brian W Evans, "Arduino Programming Notebook",

First Edition, Publisher Lulu.com, August 2007.

[14] Joshua Noble, "Programming Interactivity: A designer's guide to processing, Arduino, and Open Frameworks", First edition, Published by O'Reilly Media, Inc., July 2009.

[15] A. Goswami, T. Bezboruah and K.C. Sarma, "Design of An Embedded System For Monitoring and Controlling Temperature and Light", International Journal of Electronic Engineering Research, Volume 1 Number 1 pp. 27-36, 2009. 